Bangladesh J. Bot. 50(3): 947-954, 2021 (September) SpecialＤOI: https://doi.org/10.3329/bjb.v50i5.56449

\title{
EFFECTS OF PERLITE, GRASS CHARCOAL AND VERMICULITE ON ROOT GROWTH OF ISATIS (ISATIS TINCTORIA L. WOAD) AND SOIL NUTRIENT MIGRATION
}

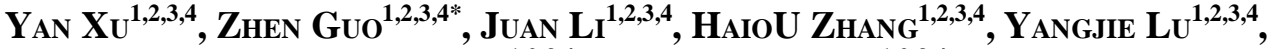 \\ Chendi Shi ${ }^{1,2,3,4}$ and Tingting $\mathrm{CAO}^{1,2,3,4}$ \\ Institute of Land Engineering and Technology, Shaanxi Provincial Land Engineering \\ Construction Group Co. Ltd., Xi'an 710075, China
}

Keywords: Perlite, Grass charcoal, Vermiculite, Soil Nutrients

\begin{abstract}
Effects of perlite, vermiculite, and grass charcoal on root growth of Isatis and soil nutrients migration were studied, and the plant growth indicators and some soil properties of upper $(0 \sim 5 \mathrm{~cm})$ and lower layer $(5 \sim 15 \mathrm{~cm})$ were analyzed. The experiment treatments were loess $(\mathrm{CK})$, loess : perlite $=3: 1(\mathrm{~A})$, loess : grass charcoal $=3: 1(\mathrm{~B})$, loess $:$ vermiculite $=3: 1(\mathrm{C})$, loess: perlite: grass charcoal $=6: 1: 1(\mathrm{~A} 1)$, loess: perlite: vermiculite $=6: 1: 1(\mathrm{~B} 1)$, loess: grass charcoal: vermiculite $=6: 1: 1(\mathrm{C} 1)$. The results showed that soil $\mathrm{pH}$ of vermiculite-containing treatments in the upper layer and grass charcoal treatment in the lower layer decreased significantly. Before planting, the available potassium and phosphorus of the upper layer were significantly higher than those of the lower layer, and soil organic matter (SOM) was slightly higher than that of the lower layer. After planting, the decrease of available potassium in the upper layer was less than that of the lower layer, and the decrease of available phosphorus and increase of SOM in the upper layer were slightly higher than that of the lower layer. In sum, it is preferred to choose B (loess : grass charcoal = $3: 1$ ) and A1 (loess: perlite: grass charcoal $=6: 1: 1$ ) to improve the soil nutrient and utilization efficiency.
\end{abstract}

\section{Introduction}

The rapid development of industrialization and urbanization has led to continuous reduction of high-quality arable land resources. Improving the amount and quality of arable land have become the key to alleviating the contradiction between human and land. Environmental materials have the advantages of largest use function, the lowest environmental load, economy and abundant reserves, thus they have broad application in soil improvement and crop yield increase (Hu et al. 2014, Xu et al. 2014). Perlite and vermiculite have a developed pore structure (Li et al. 2017, Zhang et al. 2019b), which can improve the soil tillage structure and enrich the soil moisture and nutrients (Zeng et al. 2016). Grass charcoal is rich in organic matter (Li 2012, Zhang et al. 2019a). Therefore, study of the effects of three materials on soil nutrients and plant growth is of great significance to the soil quality improvement in poor soil area.

At present, different scientists have partially studied the properties and applications of the three environmental materials. Research by Li et al (2016) showed that the bulk density of grass charcoal was $11.11 \%$ higher than that of vermiculite and $275.00 \%$ higher than that of perlite. The water-holding capacity and the aerated pores in descending order are perlite $>$ vermiculite $>$ grass charcoal and the water-holding pores in descending order are vermiculite $>$ grass charcoal > perlite. Generally, the water holding capacity and air permeability of the matrix can be improved

\footnotetext{
*Author for correspondence: <675334047@qq.com>. ${ }^{1}$ Shaanxi Provincial Land Engineering Construction Group Co., Ltd., Xi' an 710075, China. ${ }^{2}$ Key Laboratory of Degraded and Unused Land Consolidation Engineering, the Ministry of Natural and Resources of China, Shaanxi, Xi' an 710075, China. ${ }^{3}$ Shaanxi Provincial Land Consolidation Engineering Technology Research Center, Shaanxi, Xi' an 710075, China. ${ }^{4}$ Shaanxi Key Laboratory of Land Consolidation, Xi'an 710064, China.
} 
by adding certain amount of perlite (He and Xiong 2019). The acid-base buffering capacity of the three materials is grass charcoal > vermiculite > perlite, so perlite can be appropriately added to adjust the soil pH. In terms of application, Rubin et al. (2013) and Li et al. (2016) showed that grass charcoal can effectively improve the plant nutritional status and increase the soil biological activity. Xu et al. (2014) studied the properties of vermiculite in terms of nutrient content, water absorption and retention, and anti-evaporation, and showed that vermiculite has the best water retention capacity compared to oil residue, weathered coal and shale. Fang et al. (2017) showed that perlite can improve the physical and mechanical structure of soil matrix. At present, there are few quantitative researches on the effects of these three materials on soil nutrient migration and Isatis root growth, and the combination ratio is inconsistent with the research. In the present study, different proportions of perlite, grass charcoal, vermiculite and loess were used for analyzing the growth of Isatis root and soil nutrients migration in upper $(0 \sim 5 \mathrm{~cm})$ and lower layer $(5 \sim 15 \mathrm{~cm})$, to provide a scientific basis for the improvement of soil quality in poor soil areas.

\section{Materials and Methods}

The pot experiment was carried out in the Greenhouse of Qinling Field Monitoring Center Station of Institute of Land Engineering and Technology, Shaanxi Provincial Land Engineering Construction Group Co., Ltd. The test soil was selected from this Center and the initial soil physical and chemical properties were as follows: $\mathrm{pH}$ was 8.0 , conductivity was $0.40 \mu \mathrm{S} / \mathrm{cm}$, available potassium was $275.6 \mathrm{mg} / \mathrm{kg}$, available phosphorus was $175.0 \mathrm{mg} / \mathrm{kg}$, total nitrogen was $0.96 \mathrm{~g} / \mathrm{kg}$, and soil organic matter was $11.55 \mathrm{~g} / \mathrm{kg}$. The test materials as perlite, vermiculite, and grass charcoal were purchased from Shaanxi Yangling Agricultural Supply and Marketing Station. The experimental pots were plastic with a diameter of $30 \mathrm{~cm}$ and a height of $50 \mathrm{~cm}$. There were seven treatments and each with three replicates (Table 1), and a total of 21 pots with $5 \mathrm{~kg}$ of soil were used. Full and round Isatis seeds were selected for seedlings, and transplanted the better one in each pot according to the size and growth. Water and topdress were added to each pot regularly to ensure the same amount of water and fertilizer.

Table 1. Experiment design.

\begin{tabular}{ll}
\hline Number & Treatments \\
\hline CK & Loess \\
A & Loess : Perlite $=3: 1$ \\
B & Loess : Grass charcoal $=3: 1$ \\
C & Loess : Vermiculite $=3: 1$ \\
A1 & Loess : Perlite: grass charcoal $=6: 1: 1$ \\
B1 & Loess : Perlite: vermiculite $=6: 1: 1$ \\
C1 & Loess : Grass charcoal : Vermiculite $=6: 1: 1$ \\
\hline
\end{tabular}

During the harvest period, a ruler and an electronic balance were used to measure the plant height $(\mathrm{cm})$, the fresh weight $(\mathrm{g})$ of the above ground and below ground of the Isatis root. After harvest, the collected soil samples from the upper $(0 \sim 5 \mathrm{~cm})$ and lower layer $(5-15 \mathrm{~cm})$ were airdried the animal and plant residues were removed and divided into three parts. One part was passed through a $2 \mathrm{~mm}$ sieve to determine the soil $\mathrm{pH}$. The other part was passed through a $1 \mathrm{~mm}$ sieve to determine soil available potassium and available phosphorus, measured by a flame 
photometer and the ultraviolet spectrophotometer method. And another part was passed through a $0.149 \mathrm{~mm}$ sieve to determine the soil organic matter (SOM), measured by the potassium dichromate volumetric method. All data and drawing were classified and sorted by Excel 2010, SPSS 19.0 was used for analysis of variance and multiple comparisons.

\section{Results and Discussion}

The lowest and highest average plant heights were $66.0 \mathrm{~cm}$ for $\mathrm{CK}$ and $74.0 \mathrm{~cm}$ for $\mathrm{B}$, secondly was $72.6 \mathrm{~cm}$ for A1 (Fig.1). There was no significant difference in plant height among the other treatments, indicating that the addition of grass charcoal can significantly promote the plant height growth of Isatis root.

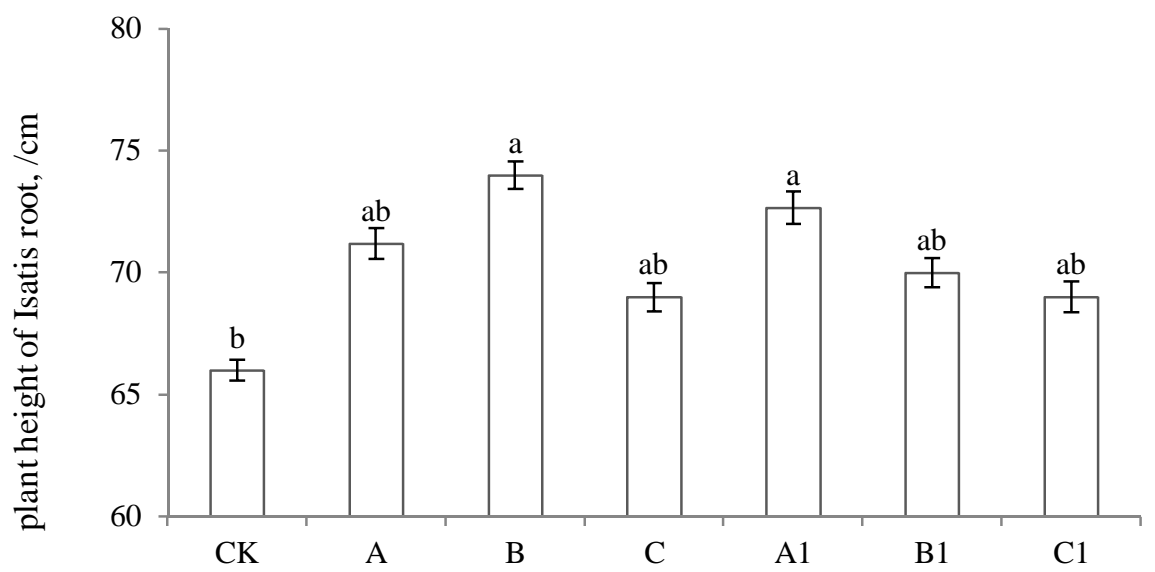

Fig. 1. Plant height of Isatis root in different treatments.

Compared with CK, the biomass of Isatis root increased after adding three materials (Fig.2). The biomass of Isatis root in B and A1 were 64.84 and $64.18 \mathrm{~g}$, respectively. The highest aboveground biomass of $\mathrm{B} 1$ was $43.02 \mathrm{~g}$, and the underground biomass of $\mathrm{B}, \mathrm{A}$ and $\mathrm{A} 1$ were 25.08, 24.26 and $23.77 \mathrm{~g}$, respectively in descending order. The root-shoot ratio of these three was also higher compared with CK.

The Isatis root grew better in perlite-containing groups than in the vermiculite-bearing groups, indicating that the synergistic effect of perlite and grass charcoal was better than vermiculite and grass charcoal. The Isatis root for B group grew best, which might be due to grass charcoal which is rich in organic matter with sufficient nutrients. The bulk density of perlite is smaller than that of vermiculite and its water holding capacity and air pores are better than vermiculite (Zhao et al. 2016), thus adding perlite to the soil is more conducive to the root respiration and extension for plant absorption. Therefore, it is more feasible to adding a certain amount of perlite in grass charcoal (Ma et al. 2017).

Compared with $\mathrm{CK}$, after adding grass charcoal, vermiculite and perlite, the soil $\mathrm{pH}$ of the upper layer $(0-5 \mathrm{~cm})$ and lower layer $(5-15 \mathrm{~cm})$ both decreased. Before planting, the average $\mathrm{pH}$ of the upper soil was 7.85 , the maximum was 8.07 for $\mathrm{CK}$, and the minimum was 7.75 for C. After planting the average soil $\mathrm{pH}$ was 7.69 , the maximum was 7.80 for $\mathrm{CK}$, and the minimum was 7.58 for $\mathrm{C} 1$. The soil $\mathrm{pH}$ of upper layer before and after planting decreased by an average of 0.16 units, 
of which CK decreased by 0.27 units, followed by $\mathrm{C} 1$ by 0.22 units, indicating that the addition of vermiculite in the upper soil can significantly reduce the soil $\mathrm{pH}$ compared to the grass charcoal and perlite.

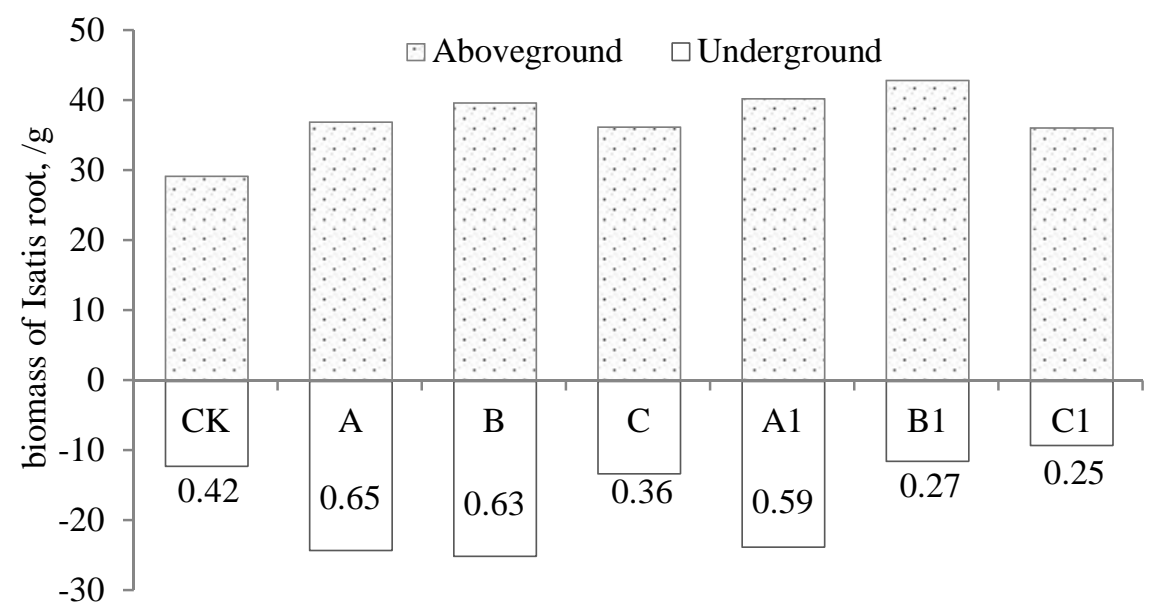

Fig. 2. Biomass of Isatis root in different treatments.

The average $\mathrm{pH}$ of the lower soil before planting was 7.77, the maximum for CK was 7.97, and the minimum for $\mathrm{B}$ was 7.67. After planting, the average soil $\mathrm{pH}$ was 7.72 , the maximum for $\mathrm{CK}$ was 7.83, and the minimum for $\mathrm{B}$ was 7.65. Before and after planting, the $\mathrm{pH}$ of the lower soil decreased by an average of 0.06 units, of which CK decreased by 0.14 units, followed by A1 of 0.10 units. The soil $\mathrm{pH}$ of the lower layer for B decreased significantly, and $\mathrm{pH}$ of the upper soil was higher than that of the lower soil before and after planting.

Soil $\mathrm{pH}$ can affect the nutrients absorption of plants. Appropriate addition of different modified substrates can alleviate the damage to plants caused by fluctuations in soil $\mathrm{pH}$ (Zhang 2019).In the present study, the soil $\mathrm{pH}$ of both upper and lower layer decreased after adding the three materials to the weakly alkaline soil (Fig. 3). The soil $\mathrm{pH}$ of the upper layer in vermiculitebearing group and the lower layer in grass charcoal-containing group decreased significantly before and after planting, while the addition of perlite has no significant effect on the soil $\mathrm{pH}$. On one hand, it might be due to the acidity and alkalinity of the material itself, on the other hand, it probably related to the lowering of $\mathrm{pH}$ by root exudates during plant growth (Wang et al. 2019).

Fig. 4 showed that compared with $\mathrm{CK}$, the available potassium of the upper $(0-5 \mathrm{~cm})$ and lower $(5-15 \mathrm{~cm})$ soil increased after adding 3 materials. The average available potassium in the upper soil before planting was $384.58 \mathrm{mg} / \mathrm{kg}$, of which the minimum was $299.61 \mathrm{mg} / \mathrm{kg}$ for CK, and the maximum was $433.68 \mathrm{mg} / \mathrm{kg}$ for B1. After planting the average soil available potassium was $169.82 \mathrm{mg} / \mathrm{kg}$, of which the maximum of B was $357.87 \mathrm{mg} / \mathrm{kg}$, and the minimum of A was $122.40 \mathrm{mg} / \mathrm{kg}$. The average decrease of available potassium in the upper soil before and after planting was $56.1 \%$. The lowest value of B was $15.7 \%$, the decrease of CK was $53.5 \%$, and the decreases of other treatments were greater than $60 \%$. Among them, A had the lowest value of $70.1 \%$.

Before planting, the average available potassium in the lower soil was $330.69 \mathrm{mg} / \mathrm{kg}$, the maximum was $375.56 \mathrm{mg} / \mathrm{kg}$ for $\mathrm{C} 1$, and the minimum was $251.25 \mathrm{mg} / \mathrm{kg}$ for CK. After planting the average soil available potassium was $127.82 \mathrm{mg} / \mathrm{kg}$, the maximum value was $309.01 \mathrm{mg} / \mathrm{kg}$ for 
$\mathrm{B}$, and the minimum value was $88.7 \mathrm{mg} / \mathrm{kg}$ for CK. Before and after planting, the average decrease of available potassium in the lower layer was $61.2 \%$. The minimum decrease of B was $8.8 \%$, and the maximum decrease of $\mathrm{C} 1$ was $74.7 \%$.
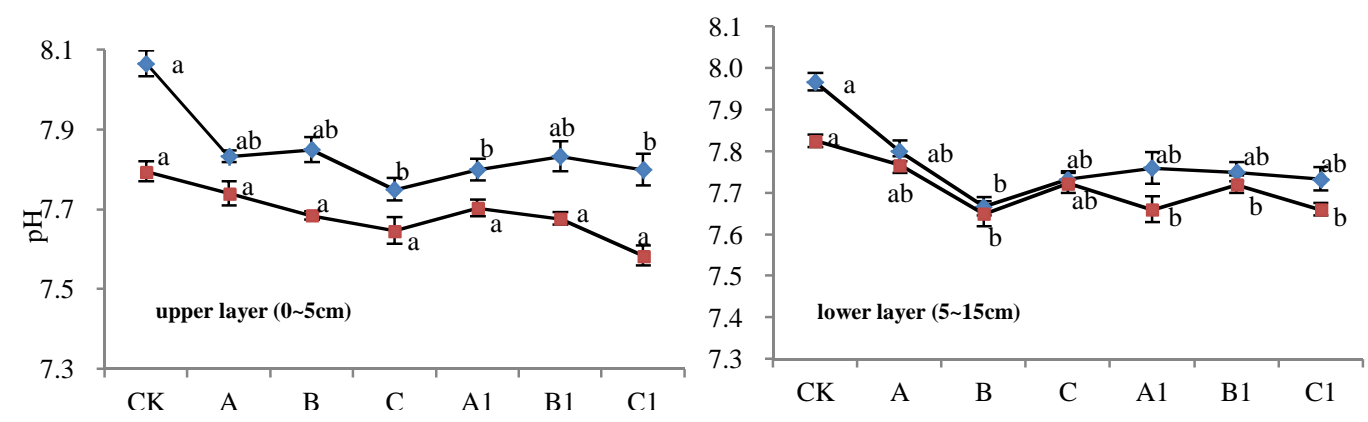

Fig. 3. Soil $\mathrm{pH}$ before and after planting in different treatments.

(The blue one: before planting, the red one: after planting).
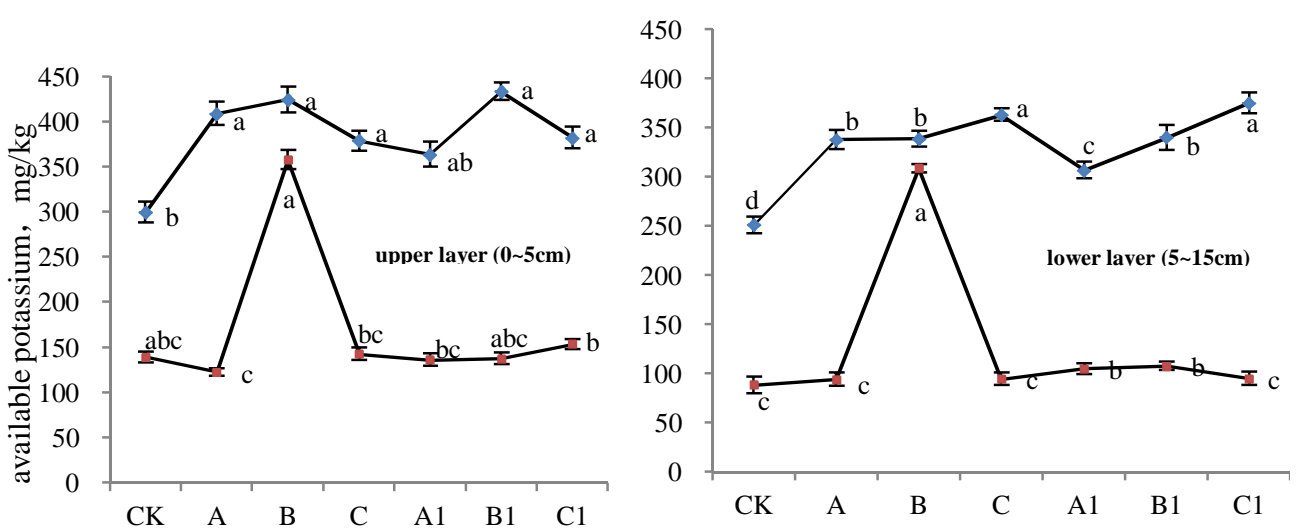

Fig. 4. The soil available potassium before and after planting in different treatments.

(The blue one: before planting, the red one: after planting)

Compared with CK, the available phosphorus in the upper layer before and after planting and the lower soil layer before planting increased after adding 3 kinds of materials, while the available phosphorus in the lower soil layer decreased slightly after planting (Fig.5). The average available phosphorus in the upper soil before planting was $233.50 \mathrm{mg} / \mathrm{kg}$, the minimum value was 177.85 $\mathrm{mg} / \mathrm{kg}$ for $\mathrm{CK}$, and the maximum value was $283.35 \mathrm{mg} / \mathrm{kg}$ for A1. The average soil available phosphorus after planting was $106.12 \mathrm{mg} / \mathrm{kg}$, the maximum value of $\mathrm{B}$ was $110.88 \mathrm{mg} / \mathrm{kg}$, the second value was $110.48 \mathrm{mg} / \mathrm{kg}$ of $\mathrm{A}$, and the minimum of CK was $99.12 \mathrm{mg} / \mathrm{kg}$. The average decrease of available phosphorus in the upper soil before and after planting was $53.6 \%$, the lowest was at CK treatment $(44.3 \%)$.

The average available phosphorus before planting in the lower soil was $190.79 \mathrm{mg} / \mathrm{kg}$, the maximum for A1 was $219.00 \mathrm{mg} / \mathrm{kg}$, the next for $\mathrm{C} 1$ was $210.80 \mathrm{mg} / \mathrm{kg}$, and the minimum for CK was $162.95 \mathrm{mg} / \mathrm{kg}$. After planting the average soil available phosphorus was $118.59 \mathrm{mg} / \mathrm{kg}$, the maximum value of $\mathrm{B} 1$ was $128.85 \mathrm{mg} / \mathrm{kg}$, and the minimum value of $\mathrm{A}$ was $105.58 \mathrm{mg} / \mathrm{kg}$. Before 
and after planting, the average decrease of available phosphorus in the lower soil was $37.3 \%$, the lowest was at CK $(22.5 \%)$.
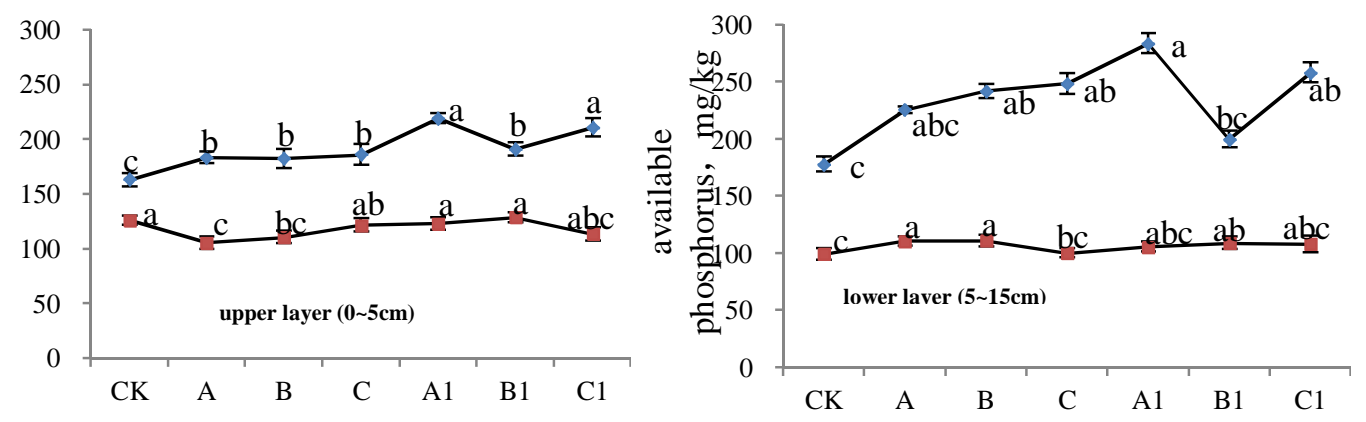

Fig. 5. The soil available phosphorus before and after planting in different treatments.

(the blue one: before planting, the red one: after planting)

The available phosphorus in the grass charcoal-bearing treatment increased more significantly, whereas in the other treatments the increase was not found significantly. Grass charcoal contributes to the promotion and preservation of soil available phosphorus, which is consistent with the result of Zhang (2019). The typical lamellar structure of vermiculite and honeycomb structure of perlite was more developed and the pores were looser. Both have good adsorption properties and can adsorb more phosphorus (Ma et al, 2017), so the mixed matrix has more phosphate fertilizer than a single matrix. Before and after planting, the soil available phosphorus of upper layer was found to be significantly higher than that of the lower, which may be related to man-made filling. While the decline of the upper soil was slightly greater than that of the lower. This might be due to the continuous infiltration of available phosphorus with water and nutrients absorption by plant roots (Kruse et al. 2015).

Different from the migration of available potassium and available phosphorus, the soil organic matter $(\mathrm{SOM})$ in the upper $(0-5 \mathrm{~cm})$ and lower $(5-15 \mathrm{~cm})$ changes differently before and after planting after adding 3 materials (Fig. 6). The average SOM in the upper soil before planting was $13.17 \mathrm{~g} / \mathrm{kg}$, the maximum for $\mathrm{C} 1$ was $15.91 \mathrm{~g} / \mathrm{kg}$, followed by B was $15.47 \mathrm{~g} / \mathrm{kg}$, and the minimum for $\mathrm{C}$ was $9.92 \mathrm{~g} / \mathrm{kg}$. After planting the average SOM was $22.78 \mathrm{~g} / \mathrm{kg}$, the maximum for B was $46.23 \mathrm{~g} / \mathrm{kg}$, the minimum for A1 was $17.38 \mathrm{~g} / \mathrm{kg}$, and the other treatments had little difference from CK. Before and after planting the average increase in SOM in the upper soil was $35.7 \%$, the minimum increase in $\mathrm{C} 1$ was $9.1 \%$, the maximum increase in $\mathrm{B}$ was $66.55 \%$, and the second was $56.57 \%$ in $\mathrm{B} 1$.

The average SOM in the lower soil before planting was $12.91 \mathrm{~g} / \mathrm{kg}$, the maximum for B was $23.37 \mathrm{~g} / \mathrm{kg}$, the next for $\mathrm{C} 1$ was $14.45 \mathrm{~g} / \mathrm{kg}$, and the minimum for $\mathrm{CK}$ was $9.17 \mathrm{~g} / \mathrm{kg}$. After planting, the average SOM was $20.66 \mathrm{~g} / \mathrm{kg}$, the maximum value of B was $45.29 \mathrm{~g} / \mathrm{kg}$, and the minimum value of $\mathrm{C}$ was $12.83 \mathrm{~g} / \mathrm{kg}$. Before and after planting, the average increase in SOM in the lower soil was 33.5\%, with the lowest increase of C1 (7.5\%), followed by A1 (19.68\%), and the remaining treatments were greater than $25 \%$, with the highest increase of B1 (57.77\%).

Soil organic matter increases significantly when grass charcoal was added to the soil, because it is rich in organic matter. Perlite and vermiculite have less organic matter, mainly promoting the SOM indirectly by improving the soil structure (Sun 2019). Therefore, the addition of vermiculite, perlite and their mixture alone has no significant effect on the SOM improvement. In general, the higher SOM in the upper layer before planting may be related to artificial filling (Meric et al, 
2011). SOM increased after planting and the increase in the upper layer was slightly higher than that in the lower layer. This might be related to the fact that the upper layer has more litter and the root system absorbs more nutrients in the lower layer.
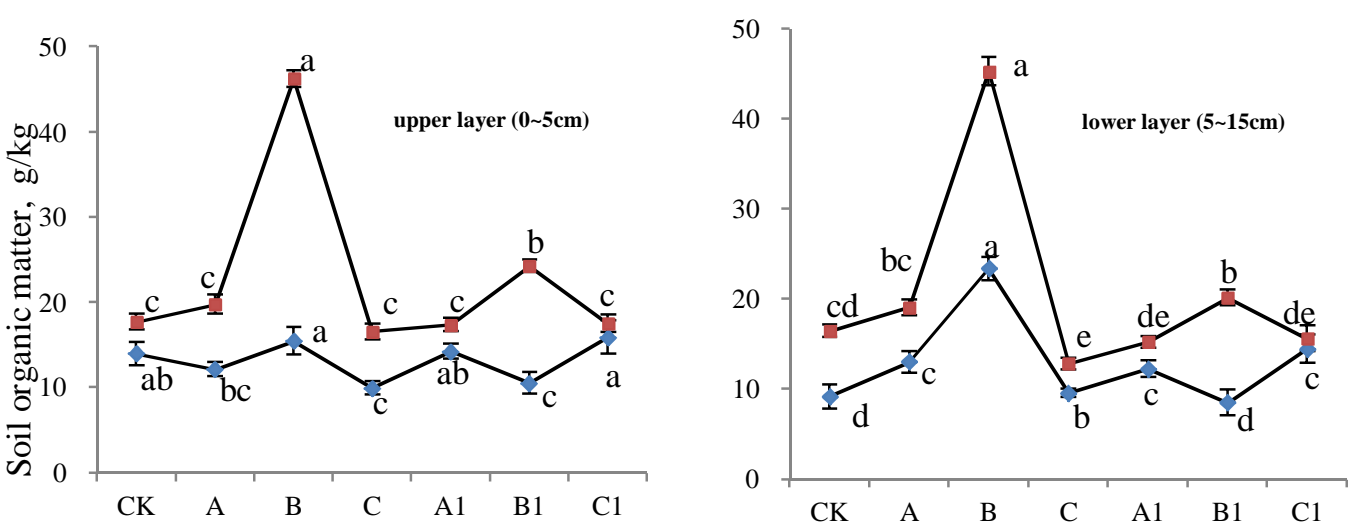

Fig. 6. The soil organic matter before and after planting in different treatments.

(The blue one: before planting, the red one: after planting)

The present study showed that the addition of three materials can effectively promote the Isatis root growth, and the addition of grass charcoal alone is most conducive. For the limited resources and high cost of grass charcoal, a certain amount of perlite can be added together to promote the growth of Isatis root. The $\mathrm{pH}$ of the upper soil in the treatment containing vermiculite decreased significantly before and after planting, and the $\mathrm{pH}$ of the lower soil in the treatment containing grass charcoal decreased significantly. The addition of perlite had no significant effect on the $\mathrm{pH}$ of the upper and lower soil.

Soil available potassium and phosphorus increased before planting, and potassium increased more significantly in the treatments with grass charcoal and vermiculite alone. The soil available phosphorus of grass charcoal-bearing treatment increased significantly and the SOM of grass charcoal-alone improved more. Overall, adding grass charcoal alone is most conducive to the retention of soil nutrients. In terms of different soil layers, the available potassium and phosphorus of the upper layer are significantly higher than those of the lower layer, and SOM was slightly higher in upper layer than that of the lower layer. After planting, the decrease of available potassium in the upper layer was less than that of the lower layer, and the decrease of available phosphorus and increase of SOM in the upper layer are slightly higher than that of the lower layer. In summary, the treatments of B (loess: grass charcoal $=3: 1$ ) and A1 (loess: perlite: grass charcoal $=6: 1: 1$ ) may be recommended to improve the soil nutrient and utilization efficiency.

\section{Acknowledgements}

This study was financially supported by the open fund of Land Engineering and Human Settlement and Civil Engineering Innovation Center (2021WHZ0093) and Shaanxi Provincial Land Engineering Construction Group internal research project (DJNY2021-26, DJNY2021-34).

\section{References}

Fang C, Li JX, Yu P and Liu AJ 2017. Experimental study on soil treatment of red mud with peat, vermiculite and perlite mixture. Shandong Chem. Ind. 46(6): 146-148. 
He J and Xiong Y F 2019. Effects of soil amendment on crop growth and soil compaction, Land Develop. Engin. Res. 4(3):49-53.

Hu YT, Shi LH, Liu DM, Tong SW, Wei MY and Sun J 2014. Effects of different perlite additions on physical and chemical properties of sewage sludge compost and growth of Tagetes patula. Chin. J. Appl. Ecol. 25(7): 1949-1954.

Kruse J, Abraham M, Amelung W, Baum C, Bol R, Lewandowsk H, Niederberger J, Oelmann Y, Ruger C and Santner J 2015. Innovative methods in soil phosphorus research: a review. J. Plant Nutr. Soil Sci. 178(1): 43-48.

Li CC, Yang LX, Xiao GY, Zeng L, He ZM and Chen J 2017. Research advances in the remodeling and functionalization of vermiculite. Bull. Chin. Ceram Soc. 36(4): 1203-1208.

Li P 2012. The influence of peat on the soil physical and chemical characteristics and tobacco quality. Hunan: Hunan Agricultural University.

Li YL, Ji YH, Yu PB, Wu ZH and Liu MC 2016. Screening test for mixed soilless culture matrix based on different physical and chemical properties. Northern Hort. 8: 36-40.

Ma Y, Liu ZH, Liu LH, Shi YJ and Huang ZB 2017. Study of composites of three kinds of environmental materials on the synergism of soil moisture conservation and nitrogen-phosphorus fertilizer efficiency. J. Agro-Environ. Sci. 36(12): 2471-2478.

Meric MK, Tuzel IH, Tuzel Y and Oztekin GB 2011. Effects of nutrition systems and irrigation programs on tomato in soilless culture. Agro. Water Manag. 99(1):19-25.

Rubin BE, Gibbons SM, Kennedy S, Hampton-Marcell J, Owens S and Gilbert JA 2013. Investigating the impact of storage conditions on microbial community composition in soil samples. PLoS One. 8(7):1-6.

Sun CC 2019. Positoining research on the effects of soil amendments addition on soil pore structure and water process. Yangling: Northwest A \& F University.

Wang Y, Li WQ and Li HH 2019. Effect of biochar and peat on the growth of Impatiens balsamina as a growth medium. J. Agro. Resour. Environ. 36(5): 656-663.

Xu XM, Wu SF, Kang BM, Feng H and Du J 2014. Study and evaluation on nutrients and water retention capacity of five natural soil amendments. J. Arid Land Resour. Environ. 28(9): 85-89.

Zeng L, Fu HY, Li CC, Chen J and He JJ 2016. Structural modification and composites of vermiculite for energy and environmental application. J. Chin. Ceram Soc. 44(8): 1226-1234.

Zhang J 2019. Effects of peat and carboloy fertilizer on soil and microorganism in root zone of kiwifruit. Yangling: Northwest A\&F University.

Zhang NY, Yan SX, Ren Q, Wang CM and Liu LJ 2019a. Water movement in soil amended with perlite particles of different sizes. J. Irrig. Drainage. 38(2): 22-28.

Zhang TT, Zhao YF, Han YY, Hao JH, Liu CJ and Fan SX 2019b. Effects of coir and vermiculite mixed substrate on the growth of lettuce seedlings. J. Beijing Agric. Coll. 34(2): 42-46.

Zhao N, He MX and Li HY 2016. Influence of peat and perlite on germination characteristics of soil seed bank. Bull. Soil Water Conserv. 36(6): 92-96.

(Manuscript received on 15 July, 2021; revised on 15 September, 2021) 